\title{
Hospital costs associated with post- traumatic stress disorder in somatic patients: a retrospective study
}

\author{
Rieka von der Warth ${ }^{1 *}$ (D) Philip Hehn², Jan Wolff ${ }^{3}$ and Klaus Kaier ${ }^{2}$
}

\begin{abstract}
Background: Post-traumatic stress disorder is likely to affect clinical courses in the somatic hospital ward when appearing as comorbidity. Thus, this study aimed to assess the costs associated with comorbid post-traumatic stress disorder in a somatic hospital and to analyze if reimbursement appropriately compensated additional costs.

Methods: The study used data from a German university hospital between 2011 and 2014, analyzing 198,819 inpatient episodes. Inpatient's episodes were included for analysis if they had a somatic primary diagnosis and a secondary diagnosis of post-traumatic stress disorder. Costs were calculated based on resource use and compared to reimbursement. Analyses were adjusted for sex, age and somatic comorbidities.

Results: $N=219$ Inpatient's episode were found with primary somatic disorder and a comorbid post-traumatic stress disorder. Inpatients episodes with comorbid post-traumatic stress disorder were compared to 34,229 control episodes, which were hospitalized with the same main diagnosis. Post-traumatic stress disorder was associated with additional hospital costs of €2311 [95\%Cl €1268 - €3355], while reimbursement rose by €1387 [€563 - €2212]. Results indicate that extra costs associated with post-traumatic stress disorder are not fully reimbursed. Male patients showed higher hospital costs associated with post-traumatic stress disorder. On average, post-traumatic stress disorder was associated with an extra length of stay of 3.4 days [2.1-4.6 days].

Conclusion: Costs associated with post-traumatic stress disorder were substantial and exceeded reimbursement, indicating an inadequate reimbursement for somatic patients with comorbid post-traumatic stress disorder.
\end{abstract}

Keywords: Post-traumatic stress disorder, Hospital costs, Comorbidity, Cost-of-illness, Diagnosis-related groups

\section{Introduction}

Post-traumatic stress disorder (PTSD) is diagnosed in individuals who were exposed to a traumatic event or who witnessed a traumatic event, when the following symptoms are observable: high physical arousal, negative thoughts leading to avoidance of trauma-related stimuli, and intrusive symptoms such as flashbacks or nightmares [DSM-V]. Individuals with PSTD have previously

\footnotetext{
* Correspondence: rieka.warth@uniklinik-freiburg.de

${ }^{1}$ Section of Health Care Research and Rehabilitation Research, Medical Center

- University of Freiburg, Faculty of Medicine, University of Freiburg,

Hugstetter Str. 49, 79106 Freiburg, Germany

Full list of author information is available at the end of the article
}

been shown to suffer from severely impaired healthrelated quality of life and struggle with a decreased life satisfaction [1,2]. PTSD was previously found to have a lifetime prevalence of $1 \%$ to $8 \%$ [3-5] with women having a higher prevalence than men [3].

There is some evidence that psychiatric comorbidities are associated with additional hospital costs. A metaanalysis found depression in particular to be associated with significantly higher hospital costs [6]. In patients with back pain undergoing disc surgery, the presence of a comorbid psychiatric disorders predicted higher direct and indirect health care costs. Associated costs were found

(c) The Author(s). 2020 Open Access This article is licensed under a Creative Commons Attribution 4.0 International License, which permits use, sharing, adaptation, distribution and reproduction in any medium or format, as long as you give appropriate credit to the original author(s) and the source, provide a link to the Creative Commons licence, and indicate if changes were made. The images or other third party material in this article are included in the article's Creative Commons licence, unless indicated otherwise in a credit line to the material. If material is not included in the article's Creative Commons licence and your intended use is not permitted by statutory regulation or exceeds the permitted use, you will need to obtain permission directly from the copyright holder. To view a copy of this licence, visit http://creativecommons.org/licenses/by/4.0/ The Creative Commons Public Domain Dedication waiver (http://creativecommons.org/publicdomain/zero/1.0/) applies to the data made available in this article, unless otherwise stated in a credit line to the data. 
even though almost no mental health services were utilized by the patients [7]. In a retrospective study assessing the associated costs of psychiatric comorbidities additional costs of $1344 €$ were found [8]. Moreover, in a study assessing the associated extra costs of mental disorders in an internal and psychosomatic department, reaction to severe stress, and adjustment disorders were found to have associated costs of $191 €$ per inpatient [9].

PTSD as main diagnosis was associated with annual direct excess health care costs ranging from 512 US-\$ to 19, 435 US- $\$$ per annum in a recent systematic review assessing the costs of illness [10]. Higher health care costs in patients with PTSD are observable across a variety of settings. Costs of patients with PTSD exceed the costs of patients without PTSD by between $8 \%$ and $75 \%$ when PTSD occurred as a result of traffic accidents [11, 12], and there is some evidence that poor psychological health and psychological disorders, such as PTSD, complicate clinical course even in routine surgical procedures [13]. Yet there are dissenting findings how PTSD affects the clinical course [14]. In a study assessing patients admitted to a Level I Trauma Centre, post-traumatic stress syndrome (PTSS) following traumatic injury was associated with an average length of stay (LOS) increase of 2 days [15], as poor psychological health in general was associated with an increased LOS in several studies [16, 17].

An increase in LOS is especially significant since LOS is not taken into account in the German Diagnosis Related Groups (G-DRG)-based reimbursement system in full proportion to the additional days of stay. DRGs are the most common hospital reimbursement system internationally, implemented in Germany in 2004. DRGs aim to create homogenous groups of patients on national level and are yearly reviewed, by approximately $16 \%$ of all hospitals in Germany providing case-cost data, clinical case data (e.g. diagnosis, procedures and sociodemographic) and additional service data on patient level [18, 19]. Within each patient group, criteria such as diagnosis, age, gender and others are then used to define financial reimbursement [20]. However, if financial reimbursement does not properly reflect costs, service providers might try to reduce costs at the expense of treatment quality [21].

To our knowledge there is no study assessing the associated hospital costs or adequate reimbursement of only PTSD as comorbid disorder in somatic patients. A previous study found additional reimbursement associated with psychiatric comorbidities in general, however, the additional reimbursement under the current G-DRG system did not cover the higher costs [8]. Thus, an inadequate reimbursement of PTSD can be hypothesized.

Cost of illness studies (COIs) display the economic costs of an illness, providing scientific evidence for political decision makers in order to take further actions, such as treatment or research $[22,23]$. Thus, knowing the costs of illness of a disorder with all influencing factors, such as the impact of comorbidities, is important to improve the health status or patients and rationalise costs due to efficiency [24]. There are different methods available for COIs, but as modelled studies are based on assumptions, some authors ask for more studies alongside clinical studies or at least within the clinical setting [25]. Thus, this study aimed to determine the impact of PTSD on in-hospital costs of patients hospitalized due to somatic diseases. Furthermore, we determine how well the G-DRG system compensates its cost. By this, this study will not only inform political decision makers on the health care costs of comorbid PTSD in somatic patients, but will also provide first information for researchers to develop new research questions on new treatments of PTSD or in-hospital routines.

\section{Methods}

Data collection was conducted at a university hospital in Germany between 2011 and 2014. Inpatients episodes were included in this study if they were hospitalized for somatic reasons and had a documented PTSD as a comorbid disorder. Presence of comorbid PTSD was defined as the presence of the International Statistical Classification of Diseases and Related Health Problems, 10th revision, German modification (ICD-10-GM) code for PTSD (ICD-10 F43.1) as secondary diagnosis. Only adult patients aged $>=18$ years were included. Inpatients episodes with a psychiatric main diagnosis were excluded. All inpatient episodes between 2011 and 2014 with an minimum age of 18 year and that had no documented comorbid psychiatric disorder were considered as potential controls (non-PTSD). Stratification by the ICD-10 main diagnosis code was applied to ensure comparability based on diagnostic and therapeutic regimes. As a result, only non-PTSD control episodes which were hospitalized with the same main diagnosis as PTSD inpatient episodes were considered for the analysis.

Resource use was obtained from the hospital's department of management. Using a bottom-up micro costing approach, full operating costs were calculated per inpatient episode according to the standardized costing system using actual costs per case occurred in conformity with the calculations of the German Institute for Hospital Reimbursement (InEK) [18]. Cost categories included are staff costs for physicians and nursing, material costs and infrastructure costs [18]. Within the three cost categories, 11 different cost centres are then calculated, generating an individual cost-matrix per episode [26]. Costs calculated are based on real costs using a full cost approach. Direct costs are based on the documented utilization using unit costs, whereas overhead costs and costs on primary costs units are based upon resource use such as, time in operating room or 
laboratory [26, 27]. Capital costs were excluded as those are not reimbursed by the G-DRGs. Thus, a health care system perspective was applied. Furthermore, the standardized InEK cost accounting scheme allows the calculation of reimbursement for each episode, which was used to assess reimbursement in this study. A detailed overview of the cost accounting scheme can be found in the cost calculation manual by the InEK [28].

Costs and reimbursements were valued and adjusted to $2014 €$. Data included main and secondary diagnoses, age, sex, LOS, discharge status and intensive care hours. Main diagnoses based on the 4-digit ICD-10 were included as categorical fixed effects, while age and sex were included as potential confounders. Furthermore, the Charlson comorbidity (CCI) index was calculated and included into the analyses as a continuous covariate, to control for severe comorbidities.

As primary endpoints we used in-hospital costs per episode calculated according to the standardized InEK costing system, as described above [18, 29]. As secondary endpoints, reimbursement and LOS per episode were analyzed analogously. Additional analyses were carried out in order to identify whether sex, age or the CCI, act as affect modifiers regarding the impact of PTSD on the primary and secondary endpoints. Therefore, their impact was tested using interaction terms. We assume that hospital costs, reimbursements and LOS were non-normally distributed and right-skewed and therefore used a generalized-linear model (GLM) with a log link and a gamma distribution for all regression analyses. We detected no outliers and no missing data. Thus, a GLM based on quasi-likelihood estimators was deemed appropriate. All analyses were conducted using Stata 15.1 (StataCorp, College Station, TX, USA).

\section{Results}

As no official checklist for COIs exits, results reported in this study follow the Consolidated Health Economic Evaluation Reporting Standards (CHEERS) where applicable [30].

In total 198,819 inpatient episodes were recorded between 2011 and 2014, of whom $N=219$ were found to be patients with a primary somatic disorder and a comorbid PTSD. $N=34,229$ inpatient episodes with the same main diagnosis as those with PTSD were found. Thus, as shown in Table 1, 219 PTSD inpatient episodes were compared to 34,229 non-PTSD inpatient episodes. PTSD inpatient episode were found to be more often female patients $(p<0.001)$, younger patients $(\mathrm{p}<0.001)$, and had less severe comorbidities as indicated by the CCI $(p<0.001)$. PTSD was associated with longer length of hospital stay. Mean costs per inpatient episode of $€ 7919$ in patients with comorbid PTSD were found, whereas patients without comorbid PTSD showed mean costs per inpatient episode of $€ 5253$. Male patients with comorbid PTSD showed higher mean costs of $€ 11,021$ per episode. Reimbursement was lower than costs per episode in patients with comorbid PTSD, with an average reimbursement of $€ 7081$ per episode. In contrast, a positive net reimbursement was observed in patients without comorbid PTSD.

After risk-adjustment, PTSD was associated with additional hospitalization costs of $€ 2311$ [95\%CI $€ 1268$ $€ 3355]$ per episode compared to non-PTSD patients hospitalized with the same main diagnosis, as shown in Table 2. Reimbursements rose by only $€ 1387$ [ $€ 563$ $€ 2212]$, indicating that the additional costs associated with PTSD were not fully reimbursed. PTSD was associated with an additional LOS of 3.4 days [2.1-4.6 days], reflecting an additional resource use. After testing for effect modifiers for the impact of PTSD, sex proved to have an impact on the effect of PTSD on reimbursement $(p=0.032)$ and LOS $(p=0.041)$. The effect of sex on hospitalization costs was not significant $(p=0.091)$. Age and further comorbidities, operationalized trough the CCI, showed no impact on the effects of comorbid PTSD. Among male patients, PTSD was associated with additional hospitalization costs of $€ 3846$ (female: $€ 1595$ ), $€ 2956$ higher reimbursements (female: €686), and an extra LOS of 5.4 days (female: 2.4 days). In contrast, no gender differences were found for the control group. See Table 2 for an overview of the regression results.

Figure 1 summarizes the results on the relative scale:

Table 1 Descriptive statistics of inpatients episodes included in the analysis

\begin{tabular}{|c|c|c|c|c|c|c|c|c|}
\hline & \multicolumn{2}{|c|}{ All PTSD episodes } & \multicolumn{2}{|c|}{ Female PTSD episodes } & \multicolumn{2}{|c|}{ Male PTSD episodes } & \multicolumn{2}{|l|}{ Controls } \\
\hline & mean/\% & SD & mean/\% & SD & mean/\% & SD & mean/\% & SD \\
\hline Costs $(€)$ & 7919 & 15,021 & 6430 & 9130 & 11,021 & 22,654 & 5253 & 9581 \\
\hline Reimbursement $(€)$ & 7081 & 14,028 & 5795 & 8287 & 9762 & 21,397 & 5340 & 8986 \\
\hline Length of hospital stay (days) & 12.04 & 15.30 & 10.54 & 10.58 & 15.17 & 21.88 & 7.89 & 8.16 \\
\hline Age (in years) & 46.21 & 16.14 & 45.67 & 15.74 & 47.35 & 17.00 & 57.70 & 18.73 \\
\hline Charlson comorbidity index & 1.29 & 2.40 & 1.32 & 2.40 & 1.24 & 2.39 & 1.93 & 2.75 \\
\hline Female sex (\%) & 68 & & 100 & & 0 & & 45 & \\
\hline Observations (N) & 219 & & 148 & & 71 & & 34,229 & \\
\hline
\end{tabular}

$S D$ standard deviation 
Table 2 Additional cost, reimbursement and length of stay associated with PTSD

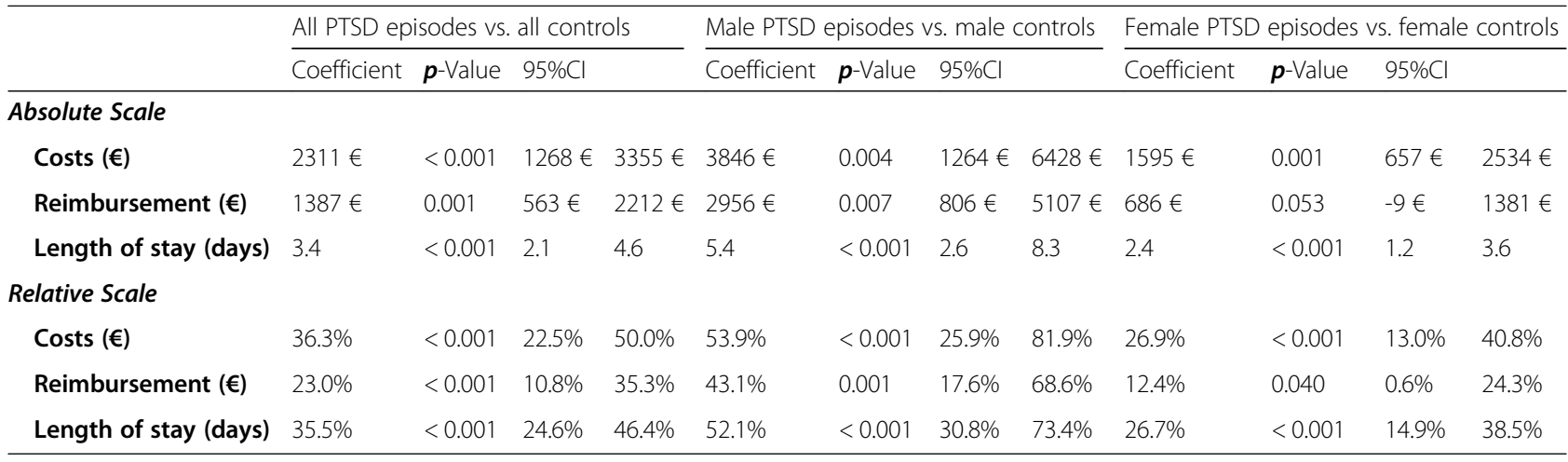

\section{Discussion}

We assessed the additional hospital costs associated with PTSD in a somatic hospital using the hospital cost and reimbursement data. Inpatient episodes of patients with PTSD differed significantly from the control group. Additional costs of PTSD during hospitalization in somatic patients were $€ 2311$ on average, whereas reimbursement rose by only $€ 1387$ on average. Thus, costs were much higher and exceeded reimbursements by more than $10 \%$, whereas in the control group reimbursements exceeded costs by $2 \%$, indicating an inadequate reimbursement in the German reimbursement system for comorbid PTSD in somatic patients. Across all measures, male PTSD patients were less frequent than their female counterparts, but were associated with substantial higher PTSDrelated excess costs, a larger cost-reimbursement gap, and a more profound PTSD-related prolongation of hospital stays than in female PTSD patients. Contrary, in psychiatric samples female gender was found to be associated with a higher LOS in previous studies [31, 32]. Generally, with an average LOS of 7.3 days in hospitals over all diagnoses, no differences between men and women can be found. However, for some diagnoses the LOS for men exceeds the LOS for women, e.g. frostbites or injuries involving multiple body parts with an LOS of 16.2 for men and 8 for women and an LOS of 13.2 for men and 8.6 for women respectively [33]. Thus, the higher LOS for men in diagnoses related to PTSD in general might be a reason for higher excess costs and reimbursement.

Prevalence of PTSD in the German population is around $2.3 \%$ in representative surveys [34-36].

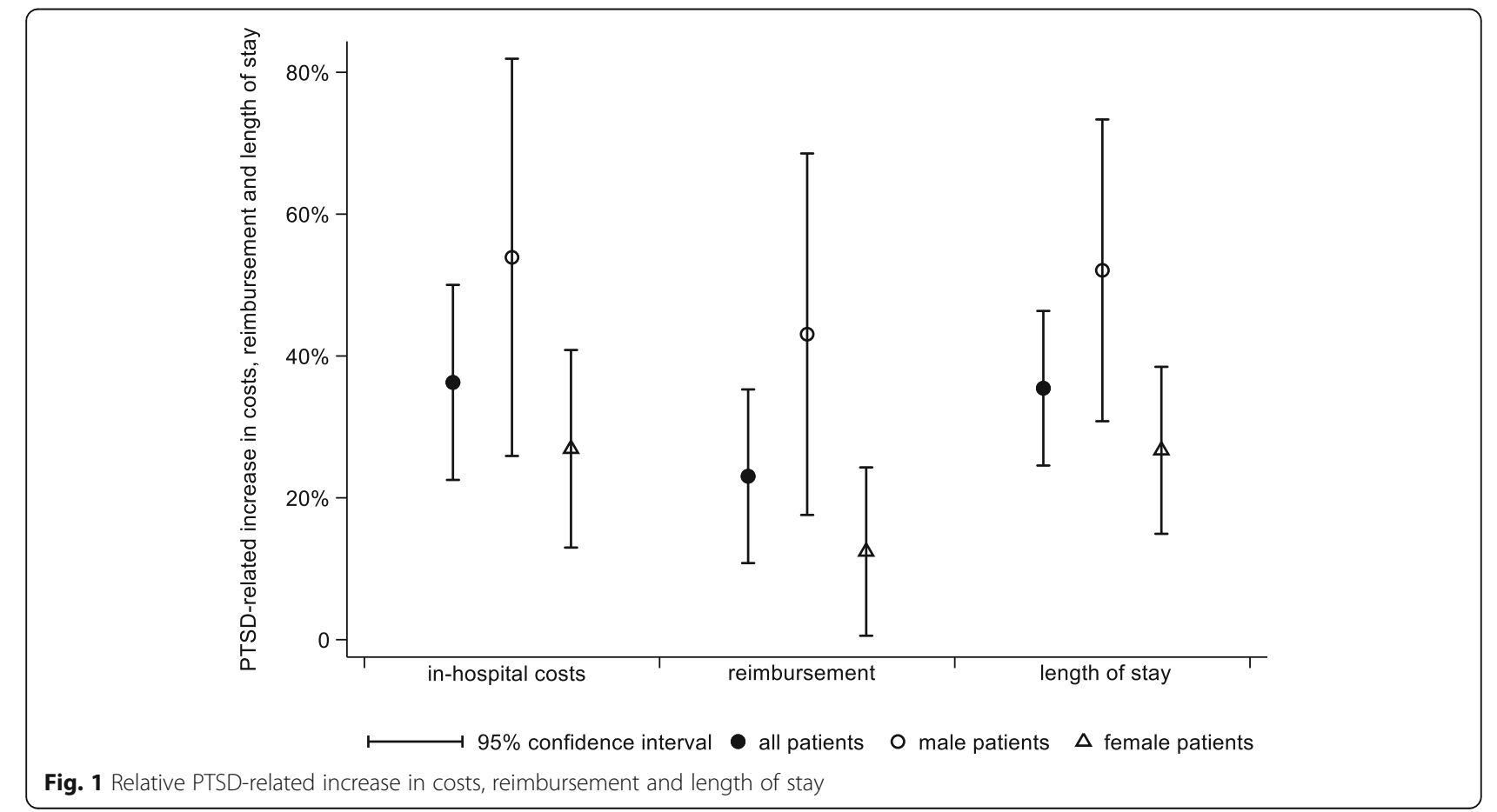


Prevalence increases with age and is generally higher in women. The higher incidence of PTSD in women is mirrored in our PTSD patient group, which had a two-thirds majority of women; however patients with PTSD were actually younger than controls, despite the increase of PTSD with age reported in the population surveys [34, 37].

We further assessed if reimbursements under the GDRG system are sufficient for patients suffering from PTSD. We found that reimbursement did increase in the presence of PTSD as comorbid disorder. However, treatment of patients with comorbid PTSD still resulted in an average lack of funding of $€ 924 €$ per episode. These findings are comparable those from previous research. Hochlehnert et al. [38] found that the German reimbursement system resulted in lack of funding of $€ 624$ per hospitalization in cardiovascular inpatients with comorbid psychiatric disorders. Comparable results were observable in a more generalized study assessing all somatic primary diagnoses and all psychiatric comorbidities in a German hospital, with an average loss of $-€ 340$ [8]. In a similar study assessing associated costs of comorbid mental disorders in a medical ward, reaction to severe stress and adjustment disorders (F43) resulted in a loss of $-€ 191$ and thus are lower than our findings. However, only five patients with a comorbid F43 diagnosis could be included in that study, without further classification of exact diagnosis (e.g. F43.0 or F43.1) [9].

Physical functionality and existence of mental disorders are correlated and therefore existence of comorbid mental disorders could be seen as a proxy for severity of physical impairment [9]. For instance, PTSD has been found to be associated with premature senescence reflected in shorter leukocyte telomere length, increased pro-inflammatory markers, and prevalence of senescence-associated medical conditions, as well as higher mortality rates $[39,40]$. An association with obesity has also been found [41].

Health effects of chronic sleep disturbances, often associated with PTSD [42-44] could be another factor contributing to the longer and more costly treatments in PTSD sufferers [45-47]. Part of the underlying mechanism also may be a tendency for PTSD patients to have a comorbid anxiety disorders and be more likely to experience events as traumatic [48], or experience adverse events such as panic attacks, or post-anaesthesia delirium [49, 50], which can complicate care. The physiological changes associated with the condition can also directly impact outcomes [51].

Previous researchers speculate that effects of psychiatric comorbidity on doctor-patient communication might play a role [14], and psychological or social factors associated with PTSD as either risk factors or symptoms might influence how timely and successfully a patient responds to symptoms of illness, influencing their clinical course $[47,52,53]$.

\section{Strengths and weaknesses}

Although single-center, our study describes a large allcomer patient cohort. We were able to describe the associated costs of comorbid PTSD in the somatic hospital under routine conditions. No special diagnostic or treatment of PTSD was conducted and thus the probability that we described the real inward treatment and financial situation is good. Due to the retrospective design using management data, we were able to include a high number of observations in our analysis. The high number should improve the robustness of the analysis. Nevertheless, the data used most likely did not contain information on different possible cofounders, such as information on previous diagnoses and treatments, and thus the omitted-variable bias cannot be excluded. For instance, higher health care costs of psychiatric comorbidities were associated with previous surgeries in a sample of back pain patients [7].

Furthermore of a total of 198,819 inpatient episodes with somatic diagnoses within the study period, only $0.11 \%$ had a documented comorbid PTSD. This is markedly lower than should be expected from estimates of PTSD prevalence in the population and means that there was likely a dark field of patients with existing, but undocumented PTSD. Internists are known not to detect psychological disorders in routine care $[54,55]$ and additionally, there is some evidence that comorbidities are not sufficiently displayed in administrative data due to different coding practices $[56,57]$, with comorbidities being less likely to be coded with more comorbidities occurring [57]. As we neither controlled for undetected PTSD cases nor for coding practice, it is not unlikely that we included patients with undocumented PTSD or other mental disorders in the control group. Several authors already recommend the integration of screenings in clinical interviews in routine care or training of the treating physicians in order to detect psychiatric comorbidities more systematically [54, 55]. There is already some evidence, that a structural screening for psychiatric comorbidities in somatic patient would lower the costs of inpatient care [58]. Furthermore, we did not know the treatment state of the PTSD cases and were not able to track whether and to what degree proper treatment of PTSD might improve the outcomes or cost of somatic hospitalizations.

Another limitation is, that we did not account for potential time-related biases and thus did not control for PTSD being diagnosed later in the clinical course. Additionally, we did not know the treatment state of the PTSD cases and were not able to track whether and to what degree proper treatment of PTSD might improve the outcomes or cost of somatic hospitalizations. Thus, the effects of PTSD on the associated costs might be overestimated. Furthermore, the German DRG system is 
in constant development, with the InEK adjusting the system in accordance with inflation and new laws every year. As major development in recent years, costs of care is additionally reimbursed to the general DRGs since 2020 [59] and thus, the overall reimbursement increased. As data used in this study were obtained between 2011 and 2014, results might differ if adjusted to new developments. However, a review by Jansen et al. [6] shows that additional costs of comorbid mental disorders are observable in different settings and reimbursement systems. Consequently, comorbid PTSD in somatic patients would most likely still be associated with additional costs in the current G-DRG system.

\section{Implications and future directions}

In this study we found PTSD to be associated with additional health care costs in a somatic inpatient hospital. These additional health care costs were not sufficiently reimbursed by the German DRG system. If the German DRG system does not properly account for PTSD as a comorbid disorder, this constitutes a disincentive effect for hospitals to properly treat PTSD patients. This effect was already discussed in previous research $[8,21]$ and other authors call for an inclusion of psychiatric comorbidities into the G-DRG system [8]. Furthermore, we suggest future research regarding the impact of PTSD on the clinical course of somatic patients. If comorbid PTSD in somatic patients has an impact not only on health care costs but also the clinical outcome, a systematic diagnostic in the clinical ward and evidence-based interventions might be useful to reduce negative outcomes and health care costs.

\section{Conclusion}

This study extends the knowledge of associated health care costs in somatic patients with comorbid mental disorders, giving a first estimate of the impact of PTSD. PTSD was associated with additional hospital costs, and reimbursement of the rendered health care services was insufficient. More evidence is needed to have a full picture of the impact of PTSD on health care costs.

\begin{abstract}
Abbreviations
PTSD : Post-traumatic stress disorder; LOS : Length of stay; DRG : Diagnosis related group; ICD-10-GM : International Statistical Classification of Disease AND Related Health Problems, 10th revision, German modification; COls : Costs of illness studies; InEK : German Institute for Hospital Reimbursement;
\end{abstract} $\mathrm{CCl}$ : Charlson comorbidity index; GLM : Generalized-linear model

\section{Acknowledgements}

We would like to thank the anonymous reviewers who contributed with their useful suggestions to improve the quality of this study.

\section{Authors' contributions}

Material preparation and analysis were performed by Jan Wolff and Klaus Kaier. The first draft of the manuscript was written by Rieka von der Warth and all authors commented on previous versions of the manuscript. All authors read and approved the final manuscript.

\section{Funding}

This research did not receive any funding. The article processing charge was funded by the German Research Foundation (DFG) and the Albert Ludwigs University Freiburg in the funding programme Open Access Publishing.

\section{Availability of data and materials}

The datasets analyzed during the current study are not publicly available due to data protection regulations.

\section{Ethics approval and consent to participate}

The study did not require ethics approval and consent to participate. All required administrative permissions were obtained in order to use the data. All data were completely de-identified.

\section{Consent for publication}

All authors have approved the final version of the manuscript.

\section{Competing interests}

Rieka von der Warth, Philip Hehn, Jan Wolff, and Klaus Kaier declare that they have no conflict of interest.

\section{Author details}

${ }^{1}$ Section of Health Care Research and Rehabilitation Research, Medical Center - University of Freiburg, Faculty of Medicine, University of Freiburg, Hugstetter Str. 49, 79106 Freiburg, Germany. ${ }^{2}$ Institute of Medical Biometry and Statistics, Faculty of Medicine and Medical Center - University of Freiburg, Freiburg, Germany. ${ }^{3}$ Department of Psychiatry and Psychotherapy, Medical Center - University of Freiburg, Faculty of Medicine, University of Freiburg, Freiburg, Germany.

Received: 16 December 2019 Accepted: 5 July 2020

Published online: 11 July 2020

\section{References}

1. van Zelst WH, de Beurs E, Beekman ATF, van Dyck R, Deeg DDH. Well-being, physical functioning, and use of health services in the elderly with PTSD and subthreshold PTSD. Int J Geriatr Psychiatry. 2006;21(2):180-8.

2. Rapaport MH, Clary C, Fayyad R, Endicott J. Quality-of-life impairment in depressive and anxiety disorders. Am J Psychiatry. 2005;162(6):1171-8.

3. Kessler RC. Posttraumatic stress disorder in the National Comorbidity Survey. Arch Gen Psychiatry. 1995;52(12):1048.

4. Bunting BP, Murphy SD, O'Neill SM, Ferry FR. Lifetime prevalence of mental health disorders and delay in treatment following initial onset: evidence from the Northern Ireland study of health and stress. Psychol Med. 2012; 42(8):1727-39.

5. The ESEMeD/MHEDEA 2000 Investigators*, Alonso J, Angermeyer MC Bernert S, Bruffaerts R, Brugha TS, et al. Prevalence of mental disorders in Europe: results from the European Study of the Epidemiology of Mental Disorders (ESEMeD) project. Acta Psychiatr Scand. 2004;109(s420):21-7.

6. Jansen L, van Schijndel M, van Waarde J, van Busschbach J. Healtheconomic outcomes in hospital patients with medical-psychiatric comorbidity: a systematic review and meta-analysis. PLoS One. 2018;13(3): e0194029.

7. Konnopka A, Löbner M, Luppa M, Heider D, Heinrich S, Riedel-Heller S, et al. Psychiatric comorbidity as predictor of costs in back pain patients undergoing disc surgery: a longitudinal observational study. BMC Musculoskelet Disord. 2012:13(1):165

8. Wolff J, Heister T, Normann C, Kaier K. Hospital costs associated with psychiatric comorbidities: a retrospective study. BMC Health Serv Res. 2018; 18(1):67.

9. Hochlehnert A, Niehoff D, Herzog W, Löwe B. Elevated costs of treatment in medical inpatients with psychiatric comorbidity are not reflected in the German DRG-system. Psychother Psychosom Med Psychol. 2007;57(2):70-5.

10. von der Warth R, Dams J, Grochtdreis T, König H-H. Economic evaluations and cost analysis in Posttraumatic Stress Disorder: a systematic review. Eur J Psychotraumatol. 2020;11(1):1753940.

11. Air TM, McFarlane AC, Psychother D. Posttraumatic stress disorder and its impact on the economic and health costs of motor vehicle accidents in South Australia. J Clin Psychiatry. 2003;64(2):175-81. 
12. O'Donnell ML, Creamer M, Elliott P, Atkin C. Health costs following motor vehicle accidents: the role of posttraumatic stress disorder. J Trauma Stress. 2005;18(5):557-61.

13. March MK, Harmer AR, Dennis S. Does psychological health influence hospital length of stay following Total knee Arthroplasty? A systematic review. Arch Phys Med Rehabil. 2018;99(12):2583-94.

14. Abrams TE, Vaughan-Sarrazin M, Rosenthal GE. Preexisting comorbid psychiatric conditions and mortality in nonsurgical intensive care patients. Am J Crit Care. 2010;19(3):241-9.

15. Sullivan E, Shelley J, Rainey E, Bennett M, Prajapati P, Powers MB, et al. The association between posttraumatic stress symptoms, depression, and length of hospital stay following traumatic injury. Gen Hosp Psychiatry. 2017:46:49-54.

16. Koopmans GT, Donker MCH, Rutten FHH. Length of hospital stay and health services use of medical inpatients with comorbid noncognitive mental disorders: a review of the literature. Gen Hosp Psychiatry. 2005;27(1):44-56.

17. Saravay SM. Lavin M. psychiatric comorbidity and length of stay in the general hospital. Psychosomatics. 1994;35(3):233-52.

18. Vogl M. Assessing DRG cost accounting with respect to resource allocation and tariff calculation: the case of Germany. Health Econ Rev. 2012;2(1):15.

19. Wiley M. From the originis of DRGs to their implementation in europe. Maidenhead: Open University Press; 2011. [cited 2020 Jun 9]. Available from: https://scholar.google.de/scholar?hl=de\&as_sdt=0\%2C5\&q=from+the+ originis+of+drgs+to+their+implementation+in+europe\&btnG=\#d=gs _ cit\&u=\%2Fscholar\%3Fq\%3Dinfo\%3ACOxmYp_RYy4J\%3Ascholar.google. com\%2F\%26output\%3Dcite\%26scirp\%3D0\%26hl\%3Dde.

20. Fetter RB, Shin Y, Freeman JL, Averill RF, Thompson JD. Case mix definition by diagnosis-related groups. Med Care. 1980;18(2):i-53.

21. Busse R, Geissler A, Aaviksoo A, Cots F, Häkkinen U, Kobel C, et al. Diagnosis related groups in Europe: moving towards transparency, efficiency, and quality in hospitals? Bmj. 2013;346:f3197.

22. Schöffski O, Über A. Grundformen gesundheitsökonomischer Evaluationen In: Gesundheitsökonomische Evaluationen. Berlin, Heidelberg: Springer; 2002. p. 175-203. Available from: https://link.springer.com/chapter/10.1007/ 978-3-642-56366-9_7. [cited 2018 Jul 16].

23. Ament A, Evers S. Cost of illness studies in health care: a comparison of two cases. Health Policy. 1993;26(1):29-42.

24. Lauterbach KW, Stock S, Brunner H. Gesundheitsökonomie - Lehrbuch für Mediziner und andere Gesundheitsberufe. Bern, Verlag Hans Huber: Hogrefe AG; 2006.

25. Poder TG. Challenges to make cost-effectiveness studies usable by decision makers. J Thorac Cardiovasc Surg. 2018;156(5):1931-2.

26. Kaier K, Heister T, Wolff J, Wolkewitz M. Mechanical ventilation and the daily cost of ICU care. BMC Health Serv Res. 2020;20(1):267.

27. Reinöhl J, Gutmann A, Kollum M. von zur Mühlen C, Baumbach H, Avlar M, et al. Transfemoral aortic valve implantation: bleeding events, related costs and outcomes. J Thromb Thrombolysis. 2013;35(4):469-75.

28. Institut für das Entgelsystem im Krankenhaus. Kalkulation von Behandlungskosten: Handbuch zur Anwendung in Krankenhäusern. 2016.

29. Quentin W, Geissler A, Scheller-Kreinsen D, Busse R. DRG-type hospital payment in Germany: the G-DRG system. Euro Obs. 2010;12(3):4-6.

30. Husereau D, Drummond M, Petrou S, Carswell C, Moher D, Greenberg D, et al. Consolidated health economic evaluation reporting standards (CHEE RS)--explanation and elaboration: a report of the ISPOR health economic evaluation publication guidelines good reporting practices task force. Value Health. 2013:16(2):231-50.

31. Tulloch AD, Fearon P, David AS. Length of stay of general psychiatric inpatients in the United States: systematic review. Adm Policy Ment Health Ment Health Serv Res. 2011;38(3):155-68.

32. Wolff J, McCrone P, Patel A, Kaier K, Normann C. Predictors of length of stay in psychiatry: analyses of electronic medical records. BMC Psychiatry. 2015; 15(1):238.

33. Gesundheitsberichterstattung des Bundes. 2017. Available from: http://www. gbe-bund.de/oowa921-install/servlet/oowa/aw92/dboowasys921.xwdevkit/ xwd init?gbe.isgbetol/xs start_neu/\&p_aid=3\&p aid=68787862\&nummer= 594\&p_sprache=D\&p_indsp=-\&p_aid=849007. [cited 2020 Apr 21].

34. Maercker A, Forstmeier S, Wagner B, Glaesmer H, Brähler E. Posttraumatische Belastungsstörungen in Deutschland: Ergebnisse einer gesamtdeutschen epidemiologischen Untersuchung. Nervenarzt. 2008;79(5):577-86.

35. Jacobi F, Höfler M, Siegert J, Mack S, Gerschler A, Scholl L, et al. Twelvemonth prevalence, comorbidity and correlates of mental disorders in Germany: the mental health module of the German health interview and examination survey for adults (DEGS1-MH): 12-month prevalence of mental disorders in Germany. Int J Methods Psychiatr Res. 2014;23(3):304-19.

36. Eichhorn S, Brähler E, Franz M, Friedrich M, Glaesmer H. Traumatic experiences, alexithymia, and posttraumatic symptomatology: a crosssectional population-based study in Germany. Eur J Psychotraumatol. 2014; 5(1):23870.

37. Glaesmer H, Gunzelmann T, Braehler E, Forstmeier S, Maercker A. Traumatic experiences and post-traumatic stress disorder among elderly Germans: results of a representative population-based survey. Int Psychogeriatr. 2010; 22(4):661-70.

38. Hochlehnert A, Niehoff D, Wild B, Jünger J, Herzog W, Löwe B. Psychiatric comorbidity in cardiovascular inpatients: costs, net gain, and length of hospitalization. J Psychosom Res. 2011;70(2):135-9.

39. Ladwig K-H, Brockhaus AC, Baumert J, Lukaschek K, Emeny RT, Kruse J, et al. Posttraumatic Stress Disorder and Not Depression Is Associated with Shorter Leukocyte Telomere Length: Findings from 3,000 Participants in the Population-Based KORA F4 Study. Ouellette MM, editor. Plos One. 2013;8(7): e64762.

40. Lohr JB, Palmer BW, Eidt CA, Aailaboyina S, Mausbach BT, Wolkowitz OM, et al. Is post-traumatic stress disorder associated with premature senescence? A review of the literature. Am J Geriatr Psychiatry. 2015;23(7): 709-25.

41. Bartoli F, Crocamo C, Alamia A, Amidani F, Paggi E, Pini E, et al. Posttraumatic stress disorder and risk of obesity: systematic review and meta-analysis. J Clin Psychiatry. 2015;76(10):e1253-61.

42. Irwin MR. Why sleep is important for health: a psychoneuroimmunology perspective. Annu Rev Psychol. 2015;66(1):143-72.

43. Oldham MA, Lee HB, Desan PH. Circadian rhythm disruption in the critically ill: an opportunity for improving outcomes*. Crit Care Med. 2016;44(1):207-17.

44. Pisani MA, Friese RS, Gehlbach BK, Schwab RJ, Weinhouse GL, Jones SF. Sleep in the intensive care unit. Am J Respir Crit Care Med. 2015;191(7):731-8.

45. Germain A. Sleep disturbances as the Hallmark of PTSD: where are we now? Am J Psychiatry. 2013;170(4):372-82.

46. Cox RC, Olatunji BO. A systematic review of sleep disturbance in anxiety and related disorders. J Anxiety Disord. 2016;37:104-29.

47. Wild J, Smith KV, Thompson E, Béar F, Lommen MJJ, Ehlers A. A prospective study of pre-trauma risk factors for post-traumatic stress disorder and depression. Psychol Med. 2016;46(12):2571-82

48. Stein MB, Höfler M, Perkonigg A, Lieb R, Pfister H, Maercker A, et al. Patterns of incidence and psychiatric risk factors for traumatic events. Int J Methods Psychiatr Res. 2002;11(4):143-53.

49. Shoum SM. Posttraumatic stress disorder: a special case of emergence delirium and anesthetic alternatives. Case Rep. 2014;3(5):58-60.

50. Wofford K, Hertzberg M, Vacchiano C. The perioperative implications of posttraumatic stress disorder. AANA J. 2012;80(6):463-70.

51. Dao TK, Chu D, Springer J, Gopaldas RR, Menefee DS, Anderson T, et al. Clinical depression, posttraumatic stress disorder, and comorbid depression and posttraumatic stress disorder as risk factors for in-hospital mortality after coronary artery bypass grafting surgery. J Thorac Cardiovasc Surg. 2010;140(3):606-10.

52. Contractor AA, Elhai JD, Ractliffe KC, Forbes D. PTSD's underlying symptom dimensions and relations with behavioral inhibition and activation. J Anxiety Disord. 2013:27(7):645-51.

53. Danielson CK, Cohen JR, Adams ZW, Youngstrom EA, Soltis K, Amstadter AB, et al. Clinical decision-making following disasters: efficient identification of PTSD risk in adolescents. J Abnorm Child Psychol. 2017;45(1):117-29.

54. Löwe B, Gräfe K, Zipfel S, Spitzer RL, Herrmann-Lingen C, Witte S, et al. Detecting panic disorder in medical and psychosomatic outpatients: comparative validation of the hospital anxiety and depression scale, the patient health questionnaire, a screening question, and physicians' diagnosis. J Psychosom Res. 2003;55(6):515-9.

55. Löwe B, Spitzer RL, Gräfe K, Kroenke K, Quenter A, Zipfel S, et al. Comparative validity of three screening questionnaires for DSM-IV depressive disorders and physicians' diagnoses. J Affect Disord. 2004;78(2): $131-40$

56. Powell $H$, Lim LL, Heller RF. Accuracy of administrative data to assess comorbidity in patients with heart disease. An Australian perspective. J Clin Epidemiol. 2001:54(7):687-93.

57. Li MH-G, Hutchinson A, Tacey M, Duke G. Reliability of comorbidity scores derived from administrative data in the tertiary hospital intensive care setting: a cross-sectional study. BMJ Health Care Inform. 2019;26(1):e000016. 
58. Valenstein M, Vijan S, Zeber JE, Boehm K, Buttar A. The cost-utility of screening for depression in primary care. Ann Intern Med. 2001;134(5):345.

59. GKV-Spitzenverband, Verband der Privaten Krankenversicherung, Deutsche Krankenhausgesellschaft. Vereinbarung zum Fallpauschalensystem für Krankenhäuser für das Jahr 2020 (Fallpauschalenvereinbarung 2020 - FPV 2020). Available from: https://www.g-drg.de/G-DRG-System_2020/ Abrechnungsbestimmungen/FPV_2020. Accessed 9 June 2020.

\section{Publisher's Note}

Springer Nature remains neutral with regard to jurisdictional claims in published maps and institutional affiliations.

Ready to submit your research? Choose BMC and benefit from:

- fast, convenient online submission

- thorough peer review by experienced researchers in your field

- rapid publication on acceptance

- support for research data, including large and complex data types

- gold Open Access which fosters wider collaboration and increased citations

- maximum visibility for your research: over $100 \mathrm{M}$ website views per year

At $B M C$, research is always in progress.

Learn more biomedcentral.com/submissions 